\title{
Safety Profile of Warfarin versus Dabigatran in Adult Patients with Non-valvular Atrial Fibrillation - A Prospective Cohort Study
}

\author{
Anam A Rabbani', Padma GM Rao', Tarun Wadhwa ${ }^{1 *}$, PK Gupta ${ }^{3}$ \\ ${ }^{1}$ Department of Clinical Pharmacy and Pharmacology, RAK College of Pharmaceutical Sciences, RAK Medical and Health Sciences \\ University, Ras Al-Khaimah, UAE. \\ ${ }^{2}$ RAK College of Pharmaceutical Sciences, RAK Medical and Health Sciences University, Ras Al-Khaimah, UAE. \\ ${ }^{3}$ Department of Cardiology, Ibrahim Bin Hamad Obaidallah Hospital, Ras Al-Khaimah, UAE.
}

\begin{abstract}
Context: Atrial fibrillation is the most commonly encountered sustained cardiac arrhythmia associated with extensive cardiovascular morbidity and mortality. Warfarin is the most recommended drug therapy for the prevention of thromboembolic events or stroke in patients with atrial fibrillation. Due to availability of newer drugs like dabigatran, the need for frequent PT/INR monitoring and bleeding risk has reduced drastically. Although, studies are lacking regarding its safety profile and therapeutic use in clinical practice. Aim: The main objective of the present study was to assess the safety profile of warfarin versus dabigatran in patients with non-valvular atrial fibrillation. Materials and Methods: This was a prospective cohort study carried out for a period of nine months. All adult patients, who were prescribed with either warfarin or dabigatran in non-valvular atrial fibrillation were included in the study. Patients were monitored initially for occurrence of adverse drug events and subsequently during their follow-up visits at 3 and 6 months. Reported ADEs were analyzed for various clinical characteristics and causality, severity and preventability using standard assessment scales. Results: A total of 75 patients (35 in warfarin and 40 in dabigatran cohort) were recruited. Out of 75, 38 patients experienced 70 ADEs (31 in warfarin and 39 in dabigatran cohort) which accounted for an overall incidence of $51 \%$. Elevated coagulation profile $(20 \%)$ followed by chest discomfort (10\%), thrombocytopenia (7.14\%), abdominal pain (7.14\%), anemia (10\%), gastritis $(5.71 \%)$ and hematemesis $(5.71 \%)$ were the most common reported ADEs among others. Dabigatran $(55.71 \%)$ was associated with higher number but less severe ADEs as compared to warfarin (44.28\%). Majority of ADEs were found to be probable (53\%) in nature, moderate $(57 \%)$ in severity, predictable $(71 \%)$ and not preventable (40\%). Conclusion: Dabigatran being a costly alternative appears to be safer than warfarin.
\end{abstract}

Key words: Adverse drug events, Anticoagulants, Dabigatran, Non-valvular atrial fibrillation, Safety profile, Warfarin.

Key Messages: Dabigatran appears to be safer than warfarin. Less frequent PT/INR monitoring, reduction in bleeding events and safer administration being the most probable reasons for preferring dabigatran in patients with non-valvular atrial fibrillation.

\section{INTRODUCTION}

Atrial Fibrillation (AF) is commonly associated with, or manifested alongwith other cardiovascular conditions which are usually characterized by "irregular" and "rapid heartbeat". The most common complaint in patients with $\mathrm{AF}$ is palpitations which results in rapid contraction rate which ranges from 100 to 160 beats/minute. ${ }^{1}$

The incidence rate of AF increases with age, as nearly $85 \%$ of patients diagnosed with $\mathrm{AF}$ are aged above 65 years old. ${ }^{2}$ It increases the risk of stroke and therefore mortality rate in patients with $\mathrm{AF}^{3}$ It is estimated that an increase in the number of individuals with AF in 2010 was 33.5 million and expected to increase about 5 million new cases each year. ${ }^{4}$ Gulf SAFE is a study conducted in the Middle East Regions. It showed high prevalence of patients with AF, among 2043 recruited patients the primary reason for the emergency visit in $45 \%$ of patients was due to $\mathrm{AF}^{5}$

The guidelines of European society of
DOI: 10.5530/ijopp.13.2.28

Address for correspondence:

Dr. Tarun Wadhwa

Assistant Professor, Department of Clinical Pharmacy and Pharmacology, RAK College of Pharmaceutical Sciences, RAK Medical and Health Sciences University, Ras Al-Khaimah, UAE.

Phone no: +971503747342

Email Id: tarun@rakmhsu.ac.ae

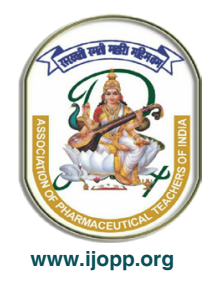


cardiology has a validated tool for the prediction of stroke risk in patients with $\mathrm{AF}$ as per CHADS2 to determine the initiation of anticoagulant therapy. CHA2DS2-VASC and HAS-BLED were used to assess the risk of bleeding along with introduction of anticoagulants. These scales used various risk factors such as congestive heart failure, age $\geq 75$ years or older, hypertension, etc. and assigned points, further the risk is stratified into high, moderate and low, showing various drug treatment options. ${ }^{6,7}$

Until now, warfarin and other Vitamin-K antagonists were used as anticoagulant medications in $\mathrm{AF}$ to prevent the risk of thromboembolic events or stroke. However, warfarin is reported to have high bleeding risk which requires strict monitoring of Prothrombin Time (PT), International Normalized Ratio (INR), drug-drug and drug-food interactions. Due to these complications, Novel Oral Anticoagulants (NOACs), that are effective, safe and which don't require strict monitoring, are preferred over warfarin. ${ }^{8}$ Dabigatran was introduced after the approval by Food and Drug Administration (FDA) on October 19, 2010 for the treatment of atrial fibrillation. ${ }^{9}$ It is an oral direct thrombin inhibitor which is more efficacious than warfarin in reducing the risk of stroke, when given at a dose of $150 \mathrm{mg}$ twice daily in patients with non-valvular atrial fibrillation; however, safety concerns are still controversial as it shows an increase in gastrointestinal bleeding. Often in the optimal clinical practice, information regarding the safety of newer medications is lacking relative to the existing medicines and comparative assessment is not available at the time of market authorization and initial use. ${ }^{10,11}$ On February 14, 2011, the American College of Cardiology (ACC) Foundation and American Heart Association (AHA) recommended the addition of dabigatran to their guidelines for management of non-valvular atrial fibrillation as a class-I recommendation. ${ }^{11}$

Adverse Drug Event (ADE) is a broad term which can arise from inappropriate prescribing of a medication (e.g., misdiagnosis, inappropriate medication, inappropriate dose, inappropriate regimen etc.), medication errors, selfmedication, side effects, allergies, genetic predispositions, Drug-Drug Interaction (DDI), drug-disease interaction, or patient non-compliance (taking more or less of a drug than the prescribed amount). ${ }^{12}$ Although ADEs and Adverse Drug Reactions (ADRs) are sometimes used interchangeably, they do not have the same meaning. An ADR refers to adverse effects of medications when they are used appropriately while ADEs in addition includes medication errors which are preventable. There are number of consequences, which range from mild allergic reaction to permanent harm, thereby causing morbidity and mortality as well as increase in the overall healthcare cost. ${ }^{13}$ It is reported that each year more than $7,70,000$ people die or are injured during hospital stay due to ADEs, which may cost $\$ 5.6$ million of the overall healthcare costs. ${ }^{14}$ The approval process of dabigatran took place in a large phase III clinical trial, which reported similar risk of bleeding with warfarin versus dabigatran in NVAF patients. In the trial, two doses $110 \mathrm{mg}$ and $150 \mathrm{mg}$ of dabigatran were compared which have been non-inferior to warfarin, in terms of efficacy and safety outcomes for the prevention of stroke, systemic embolism and reduction in the risk of intracerebral hemorrhage. ${ }^{15}$ Another recent retrospective Medicare data analysis study on dabigatran's safety highlighted that the incidence of bleeding (33\% versus $27 \%$ ) was higher than with warfarin, major bleeding $(9 \%$ versus $6 \%)$ and gastrointestinal bleeding (17\% versus 10\%). Intracranial hemorrhage occurred more often with warfarin than dabigatran $(1.8 \%$ versus $0.6 \%){ }^{16,17}$ Another study revealed higher hemorrhagic stroke rates in Asians due to warfarin compared to non- Asians despite similar blood pressure, age or INR value, however, dabigatran benefits were consistent among both the cohorts. ${ }^{18}$ The cost associated with the use of dabigatran is another major concern and non-compliance issue in patients with low income financial status. In United Kingdom (UK), the estimated total costs were $\$ 143,193$ for warfarin, comparatively less than $\$ 164,576$ for low $\$ 168,398$ for high-dose dabigatran. ${ }^{19,20}$ A study conducted in United Arab Emirates (UAE) and Kingdom of Saudi Arabia (KSA) recruited 157 and 152 patients respectively, the majority of which were diagnosed with chronic (persistent or permanent) AF (81\% in UAE, 64\% in KSA). The mean total annual costs per patient attributable to AF were $\$ 1,151$ (standard deviation (SD): $\$ 1,796$ ) per person in the UAE and $\$ 3,001$ (SD: $\$ 3,502$ ) per person in KSA, with monitoring costs being the largest contributor to costs in both countries ( $47 \%$ and $66 \%$, respectively). ${ }^{21}$

Although, dabigatran has been recently introduced in UAE hospitals for its clinical use among the National and non-national population with diverse characteristics, no prospective studies have been conducted regarding its safety profile in atrial fibrillation patients. Hence, the main objective of the present study was to compare the safety profile of dabigatran with warfarin in patients with NVAF.

The main objective of the present study was to assess the safety profile of warfarin versus dabigatran in adult patients with non-valvular atrial fibrillation. Secondary objectives of the study were to monitor ADEs associated with warfarin or dabigatran in patients with non-valvular atrial fibrillation, characterize ADEs based on various parameters such as demographics, co-morbid conditions, organ system affected, type of ADE, individual reaction, 
predisposing factors, management and outcome of ADEs, analyze the reported ADEs for causality, severity and preventability using standard assessment scales and estimate the direct cost attributable to ADEs.

\section{MATERIALS AND METHODS}

The present study was a prospective observational cohort, non-interventional study which was conducted in the cardiology department of a secondary care hospital, Ibrahim Bin Hamad Obaidallah Hospital, Ras AlKhaimah, UAE for a period of nine months (Oct. 2015 to June 2016). This study was initiated after obtaining approval from the Research and Ethics committee of RAK Medical and Health Sciences University (RAKMHSU) and Ras Al-Khaimah (RAK) Research and Ethics Committee.

Patients were enrolled into the study by attending the clinical rounds with clinicians, clinical meetings and out-patient clinic visits. Prior information regarding the study was conveyed to the cardiology department and hospital pharmacy division for the better recruitment of eligible patients. All adult patients who were prescribed with either warfarin or dabigatran in NVAF for the prevention of stroke or systemic embolism were included in the study. Patients receiving anti-thrombotics for other clinical conditions were excluded.

Baseline data pertaining to their previous history, allergy, disease condition, investigations and medications was collected using the electronic patient medical records and documented in the patient profile forms, ADR notification and documentation forms designed for the study purpose. Patients were monitored for the occurrence of ADEs during hospital stay, at the time of discharge and on their subsequent follow-up visits at 3 months and 6 months.

The main outcome of the study was safety events like bleeding events and any other adverse drug events. Reported adverse drug events were analyzed for their causality, severity and preventability using standard assessment scales.

Direct cost attributable to ADEs was assessed at the time of discharge and subsequent follow-up visits at 3 months and 6 months. In case if the patient was unable to come for follow-up visit, a telephonic interview was conducted to ensure the safety of ongoing warfarin or dabigatran. Details pertaining to the same were recorded in the follow-up documentation form. The parameters which were considered for the estimation of direct cost include hospitalization cost, consultation and sub-consultation charges, bed charges, nursing charges, investigation charges and medication cost.

\section{Statistical Analysis}

Data collected from the present study was entered into the Microsoft Excel sheet for analysis using the Statistical Package for the Social Sciences (SPSS) Version 23.0. Descriptive statistics was presented in the form of frequency, percentage, mean and standard deviation (Mean $\pm \mathrm{SD}$ ). Independent t-test was used to compare the number of ADEs and variables in both cohorts. ANOVA and Chi-square tests were performed to find out the association between the ADEs and sociodemographic parameters, comorbid conditions and concurrent medications. Multivariate regression was applied for the dependent variable such as age, gender, nationality, comorbidities and polypharmacy to analyze the predictors of ADEs. P-value of less than 0.05 was considered as statistically significant.

\section{RESULTS}

A total of 75 patients, including 40 patients in dabigatran cohort and 35 patients in warfarin cohort, were enrolled in the present study.

The average length of hospital stay was observed to be $4.85 \pm 11.5$ days in the study.

\section{Incidence of Adverse Drug Events}

A total of 70 ADEs (31 in warfarin vs. 39 in dabigatran) were observed among 38 patients. At the time of followup, a total of $45 \mathrm{ADEs}$ were observed among 24 patients. Eleven patients were observed as lost to follow-up during 3 months visit whereas 14 patients could not complete their six months follow-up during the study period. The overall incidence rate of ADEs was recorded as $50.67 \%$. In 6 patients, ADE was the reason for hospital admission which accounted for an incidence of $8 \%$.

\section{Demographics- Age wise distribution}

The age of patients ranged between 31 and 103 years with an average mean of $70 \pm 14.6$ years. The maximum number of ADEs [31 (44.28\%) and $27(38.5 \%)$ ] were observed in elderly patients aged more than 65 years. The significant difference was observed in the age groups among both the cohorts ( $p$-value $=0.002)$ as dabigatran [35 $(87.5 \%)$ ] users were higher in number in the age group above 65 years as tabulated in Table 1 . 


\section{Demographics- Gender wise distribution}

Out of 75 patients, majority of patients were female $(53.33 \%)$ as compared to male (46.67\%). Among males, $19(47.5 \%)$ patients were enrolled in dabigatran cohort whereas $16(45.71 \%)$ patients in warfarin cohort. On the other hand, 21 (52.5\%) female patients were enrolled in dabigatran cohort whereas 19 (54.28\%) female patients in warfarin cohort. Female (53.33\%) preponderance was observed over male $(46.67 \%)$ in the present study (Table 1).

Male preponderance $111(55 \%)$ in warfarin vs. 7 (54\%) in dabigatran] was observed over female with respect to the occurrence of ADEs [9 (45\%) in warfarin and 6 (46\%) in dabigatran] in both the treatment groups (Table 1).

\section{Nationality}

Majority of patients [53 (70.67\%)] included in the study were Emiratis [21 (60\%) in warfarin vs $32(80 \%)$ in
Dabigatran] followed by expatriates (Table 2).

\section{$\mathrm{CHA}_{2} \mathrm{DS}_{2}-\mathrm{VASc}$ and HAS-BLED score}

For the assessment of risk factors and bleeding tendencies, the mean $\mathrm{CHA}_{2} \mathrm{DS}_{2}$-VASc score and mean HAS-BLED score was calculated and recorded as $3.7 \pm$ 1.44 and $2 \pm 1.02$ respectively as represented in Table 3 .

\section{Associated co-morbidities and concurrent medications}

On evaluation of concurrent medications among enrolled patients with multiple co-morbidities, significant numbers of ADEs $(p=0.001)$ were recorded with clopidogrel $(p=0.018)$ and NSAIDs $(p=0.010)$ (Table 4 and 5).

Due to the presence of multiple co-morbidities, majority of patients were found to be on multiple medications (polypharmacy) as depicted in Table 6.

Table 1: Demographics (age and gender wise distribution).

\begin{tabular}{|c|c|c|c|c|}
\hline Demographic characteristics & 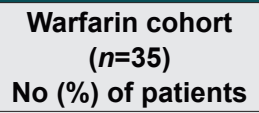 & 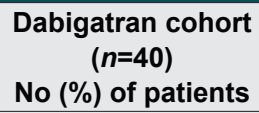 & $\begin{array}{c}\text { Total } \\
(n=75) \\
\text { No }(\%) \text { of patients }\end{array}$ & $p$-value \\
\hline \multicolumn{5}{|l|}{$\begin{array}{c}\text { Age } \\
\text { (in years) }\end{array}$} \\
\hline$<55$ & $9(25.71)$ & $1(2.5)$ & $10(13.33)$ & \\
\hline $55-64$ & $6(17.14)$ & $4(10)$ & $10(13.33)$ & \\
\hline $65-74$ & $12(34.28)$ & $17(42.5)$ & $29(38.67)$ & \\
\hline$\geq 75$ & $8(22.85)$ & $18(45)$ & $26(34.67)$ & \\
\hline Subtotal & $35(100)$ & $40(100)$ & $75(100)$ & $0.002^{*}$ \\
\hline Mean \pm SD & $70 \pm 14.6$ & & & \\
\hline Age group $<65$ & $14(40)$ & $5(12.5)$ & $19(25.33)$ & \\
\hline Age group $\geq 65$ & $21(60)$ & $35(87.5)$ & $56(74.67)$ & \\
\hline Subtotal & $35(100)$ & $40(100)$ & $75(100)$ & \\
\hline \multicolumn{5}{|l|}{ Gender } \\
\hline Male & $16(45.71)$ & $19(47.5)$ & $35(46.67)$ & \\
\hline Female & $19(54.28)$ & $21(52.5)$ & $40(53.33)$ & \\
\hline Subtotal & $35(100)$ & $40(100)$ & $75(100)$ & 0.761 \\
\hline
\end{tabular}

$\mathrm{n}=$ number of patients, figure in the parenthesis represent percentage, *ANOVA test.

Table 2: Demographics (Nationality wise distribution).

\begin{tabular}{|c|c|c|c|c|}
\hline Demographic characteristics & $\begin{array}{c}\text { Warfarin cohort } \\
(n=35)\end{array}$ & 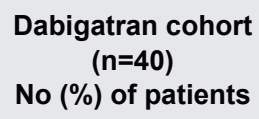 & $\begin{array}{c}\text { Total } \\
(n=75) \\
\text { No }(\%) \text { of patients }\end{array}$ & $p$-value \\
\hline \multicolumn{5}{|l|}{ Nationality } \\
\hline Emirati & $21(60)$ & $32(80)$ & $53(70.67)$ & \\
\hline Non--Emirati & $14(40)$ & $8(20)$ & $22(29.33)$ & \\
\hline Subtotal & 35 (100) & $40(100)$ & $75(100)$ & 0.261 \\
\hline
\end{tabular}

$\mathrm{n}=$ number of patients, figure in the parenthesis represent percentage, *ANOVA test 
Table 3: Risk score in both the treatment groups.

\begin{tabular}{|c|c|c|c|}
\hline Risk Score & 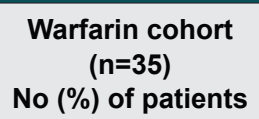 & 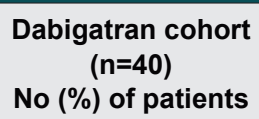 & $\begin{array}{c}\begin{array}{c}\text { Total } \\
(n=75)\end{array} \\
\text { No }(\%) \text { of patients }\end{array}$ \\
\hline \multicolumn{4}{|c|}{ CHA2DS2-VASc score* } \\
\hline $0-1$ & $5(14.28)$ & $1(2.5)$ & $6(8)$ \\
\hline 2 & $5(14.28)$ & $3(7.5)$ & $8(10.67)$ \\
\hline $3-4$ & $19(54.28)$ & $18(45)$ & $37(49.33)$ \\
\hline $5-6$ & $6(17.14)$ & $18(45)$ & $24(32)$ \\
\hline Mean \pm SD & & & $3.7 \pm 1.44$ \\
\hline \multicolumn{4}{|c|}{ HAS - BLED score } \\
\hline $0-1$ & $14(40)$ & $13(32.5)$ & $27(36)$ \\
\hline $2-3$ & $17(48.57)$ & $24(60)$ & $41(54.67)$ \\
\hline $4-5$ & $4(11.43)$ & $3(7.5)$ & $7(9.33)$ \\
\hline Mean \pm SD & & & $2 \pm 1.02$ \\
\hline
\end{tabular}

$\mathrm{n}=$ number of patients, figure in the parenthesis represent percentage, *ANOVA test.

Table 4: Associated co-morbidities and distribution of patients in both the treatment groups.

\begin{tabular}{|c|c|c|c|}
\hline $\begin{array}{l}\text { Associated } \\
\text { co-morbidities }\end{array}$ & $\begin{array}{c}\begin{array}{c}\text { Warfarin cohort } \\
(n=35)\end{array} \\
\text { No }(\%) \text { of patients }\end{array}$ & $\begin{array}{l}\text { Dabigatran cohort } \\
(n=40) \\
\text { No }(\%) \text { of patients }\end{array}$ & $\begin{array}{c}\begin{array}{c}\text { Total } \\
(n=75) \\
\text { No }(\%) \text { of patients }\end{array} \\
\end{array}$ \\
\hline $\begin{array}{l}\text { Prior stroke, Transient Ischemic } \\
\text { attack or systemic embolism }\end{array}$ & $2(5.71)$ & $8(20)$ & $10(13.33)$ \\
\hline Hypertension a & $26(74.28)$ & $38(95)$ & $64(85.33)$ \\
\hline Heart Failure & $4(11.43)$ & $10(25)$ & $14(18.67)$ \\
\hline Diabetes Mellitus type (II)a & $16(45.71)$ & $23(57.50)$ & $39(52)$ \\
\hline Myocardial Infarction a & $11(31.43)$ & $13(32.5)$ & $24(32)$ \\
\hline Chronic Kidney Disease & $6(17.14)$ & $5(12.50)$ & $11(14.67)$ \\
\hline Liver Disease & $2(5.71)$ & 0 & $2(2.67)$ \\
\hline Others Thyroid disorders & $4(11.43)$ & $3(7.5)$ & $7(9.33)$ \\
\hline Gastrointestinal disorders & $2(5.71)$ & $2(5)$ & $4(5.33)$ \\
\hline Bronchial Asthma & $2(5.71)$ & $3(7.5)$ & $5(6.67)$ \\
\hline
\end{tabular}

$\mathrm{n}=$ number of patients, figure in the parenthesis represent percentage, aChi-square $\mathrm{p}$-value $=0.044$.

\section{Adverse drug events}

The number of adverse drug events was significantly higher among inpatients $(p$-value $=0.004)$. The most common suspected ADEs were elevated coagulation profile $(20 \%)$, anemia $(10 \%)$, chest discomfort $(10 \%)$, gastritis $(5.71 \%)$, hematemesis $(5.71 \%)$, hematuria (5.71\%), abdominal pain (7.14\%) and thrombocytopenia $(7.14 \%)$. In the warfarin cohort, majority of the ADEs were elevated coagulation profile $(45.16 \%)$ and chest discomfort (13\%) followed by anemia (9.68\%), hemoptysis $(6.45 \%)$, rectal bleeding $(6.45 \%)$ and skin bruises and redness (6.45\%). Dabigatran cohort presented with higher number of ADEs, especially anemia $(10.26 \%)$, mild gastritis $(10.26 \%)$, hematuria $(10.26 \%)$, thrombocytopenia $(10.26 \%)$, abdominal pain $(10.26 \%)$ followed by chest discomfort $(7.69 \%)$, hemoptysis $(5.13 \%)$ and increased creatinine clearance $(5.13 \%)$ as presented in Table 7 . There was a significant association observed between the drug and type of ADEs $(\phi$ value $=0.002)$ with a strong positive association $(\varphi=0.756)$.

\section{Organ system affected by ADEs}

The gastrointestinal (28.2\%) and renal (16.6\%) systems Indian Journal of Pharmacy Practice, Vol 13, Issue 2, Apr-Jun, 2020 
Table 5: Concomitant drug therapy and distribution of patients in both the treatment groups.

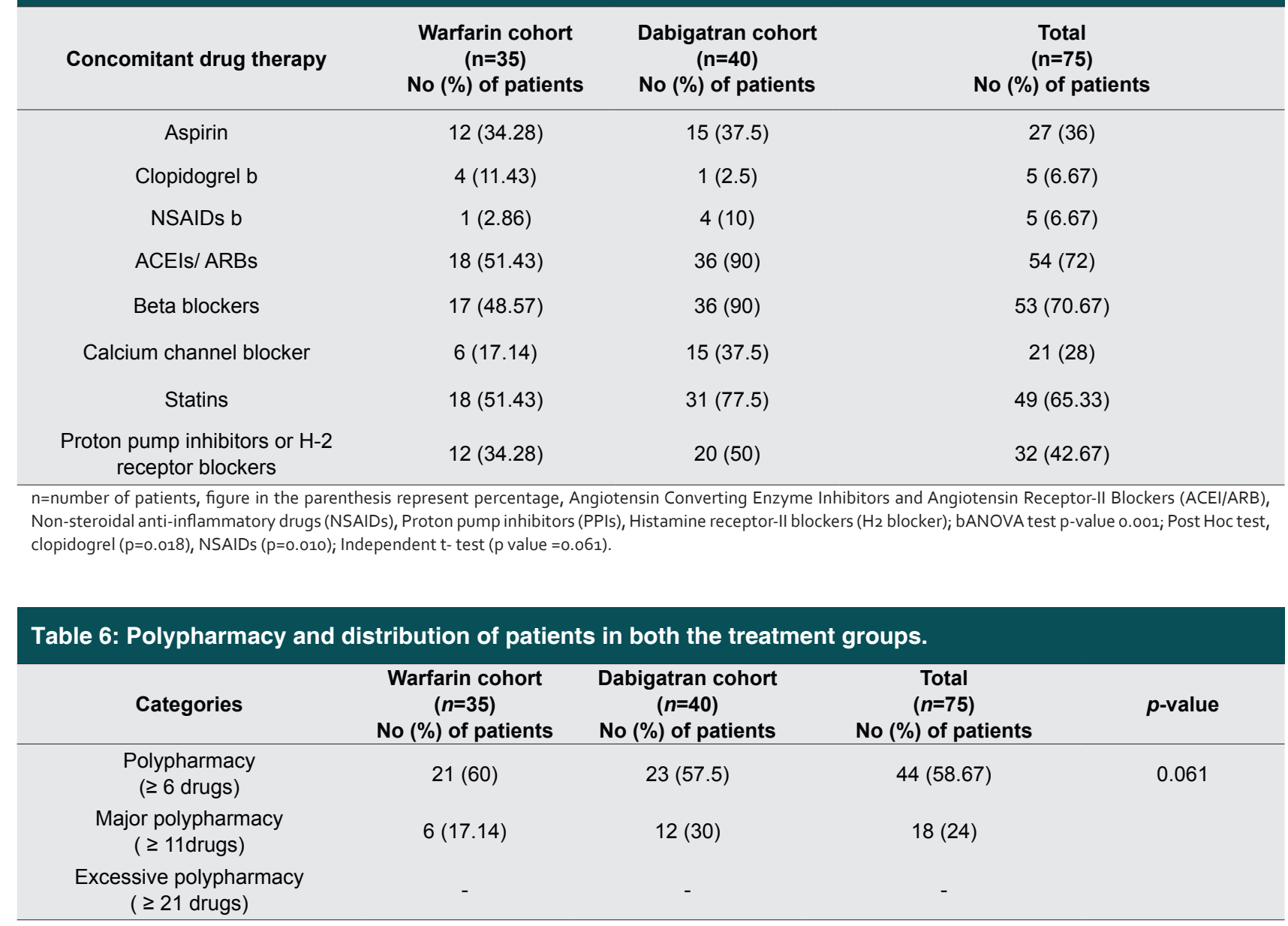

$\mathrm{n}=$ number of patients, figure in the parenthesis represent percentage, remaining patients were on less than 6 drugs, Independent $t$ - test.

\section{Table 7: Suspected adverse drug events.}

\begin{tabular}{|c|c|c|c|}
\hline Suspected ADEs\# & $\begin{array}{l}\text { Warfarin cohort }(n=31) \\
\text { No }(\%) \text { of ADEs }\end{array}$ & $\begin{array}{c}\text { Dabigatran cohort }(n=39) \\
\text { No }(\%) \text { of ADEs }\end{array}$ & $\begin{array}{c}\text { Total } \\
(n=70) \\
\text { No }(\%) \text { of ADEs }\end{array}$ \\
\hline $\begin{array}{l}\text { Elevated Coagulation Profile (INR, PT, } \\
\text { APTT) }\end{array}$ & $14(45.16)^{*}$ & 0 & $14(20)$ \\
\hline Anemia & $3(9.68)$ & $4(10.26)$ & $7(10)$ \\
\hline Mild Gastritis & 0 & $4(10.26)^{*}$ & $4(5.71)$ \\
\hline Hematemesis (Malena) & $1(3.22)$ & $3(7.69)$ & $4(5.71)$ \\
\hline Rectal Bleeding & $2(6.45)$ & 0 & $2(2.86)$ \\
\hline Hematuria & 0 & $4(10.26)$ & $4(5.71)$ \\
\hline Thrombocytopenia & $1(3.22)$ & $4(10.26)$ & $5(7.14)$ \\
\hline Abdominal pain & $1(3.22)$ & $4(10.26)$ & $5(7.14)$ \\
\hline Chest discomfort & $4(13)$ & $3(7.69)$ & $7(10)$ \\
\hline Hemoptysis & $2(6.45)$ & $2(5.13)$ & $4(5.71)$ \\
\hline Increased Creatinine Clearance & 0 & $2(5.13)$ & $2(2.86)$ \\
\hline Epistaxis & 0 & $1(2.56)$ & $1(1.43)$ \\
\hline Gum bleeding & 0 & $1(2.56)$ & $1(1.43)$ \\
\hline Elevation of Hepatic enzymes (ALT) & 0 & $1(2.56)$ & $1(1.43)$ \\
\hline Dizziness & 0 & $1(2.56)$ & $1(1.43)$ \\
\hline Hypotension & 0 & $1(2.56)$ & $1(1.43)$ \\
\hline Tachycardia & 0 & $2(5.13)$ & $2(2.86)$ \\
\hline Palpitations & $1(3.22)$ & $2(5.13)$ & $3(4.28)$ \\
\hline Subtotal & 31 (100) & 39 (100) & 70 (100) \\
\hline
\end{tabular}

$\mathrm{n}=$ number of ADEs, figure in the parenthesis represent percentage, *Independent t-test ( $p$-value=0.004), Chi-square ( $p$-value=0.002), Phi value (o.756), \#ADEs-Adverse drug events. 
were mainly affected in dabigatran cohort as compared to less number in warfarin cohort (Table 7).

All the dependent variables were analyzed statistically by multivariate regression analysis and results revealed that age, gender, nationality, polypharmacy and number of comorbidities were not significant $(p>0.05)$ predictors for ADEs (Table 8).

\section{Management of ADEs}

Most of the ADEs were managed by altering the dose (54.28\%) monitoring the patient without any change in drug therapy (35.71\%) and withdrawing the drug in 7 $(10 \%)$ ADEs. Suspected drug was de-challenged in 22 patients [39 $(55.7 \%)]$ and then re-challenged, of whom in 4 cases [7 (10\%)], reaction reappeared (Table 3). Few adverse drug events were managed by either specific treatment (Injection protamine sulphate) or symptomatic therapy (Inj. pantaprazole given for gastritis, Inj. hyoscine for abdominal pain, etc) in both the treatment groups [warfarin $(8,26 \%)$ and $(15,38.5 \%)$ dabigatran cohort]. Majority of cases [54 (77.14\%)] had recovered in both the groups [26 (83.87\%) in warfarin cohort and $28(71.79 \%)$ in dabigatran cohort] (Table 9).

\section{Assessment of ADEs}

\section{Causality assessment by WHO probability scale}

Adverse drug events were analyzed using WHO probability scale for the causality assessment. Majority of the suspected ADEs were probable (52.86\%), followed by certain $(12.86 \%)$, possible $(21.43 \%)$ and unlikely $(12.86 \%)$ in both the groups (Table 10).

\section{Severity assessment by Hartwig et al. scale}

Severity assessment of ADEs revealed both moderate (57.14\%) and mild (37.14\%) type of ADEs, but none of the ADE was fatal (Table 10).

\section{Predictability assessment}

Table 8: Multivariate regression analysis of the dependent variables and ADEs.

\begin{tabular}{ccccc}
$\begin{array}{c}\text { Dependent } \\
\text { Variables }\end{array}$ & B & Beta & t & P \\
\hline Gender & -0.186 & -0.089 & -0.746 & 0.458 \\
Age & -0.13 & -0.132 & -0.948 & 0.346 \\
Nationality & 0.037 & 0.016 & 0.133 & 0.894 \\
$\begin{array}{c}\text { Polypharmacy } \\
\text { No. of }\end{array}$ & 0.391 & 0.142 & 1.082 & 0.283 \\
comorbidities & 0.146 & 0.191 & 1.469 & 0.146 \\
\hline
\end{tabular}

Table 9: Management, treatment and outcome of ADEs in both the treatment groups.

\begin{tabular}{|c|c|c|c|}
\hline $\begin{array}{l}\text { Treatment } \\
\text { strategies }\end{array}$ & $\begin{array}{c}\text { Warfarin } \\
\text { Cohort } \\
(n=31) \\
\text { No }(\%) \text { of } \\
\text { ADEs }\end{array}$ & $\begin{array}{c}\text { Dabigatran } \\
\text { Cohort }(n=39) \\
\text { No }(\%) \text { of } \\
\text { ADEs }\end{array}$ & $\begin{array}{c}\begin{array}{c}\text { Total } \\
(n=70)\end{array} \\
\text { No }(\%) \text { of } \\
\text { ADEs }\end{array}$ \\
\hline \multicolumn{4}{|l|}{ Management } \\
\hline $\begin{array}{c}\text { Drug } \\
\text { withdrawn }\end{array}$ & $1(3.22)$ & $6(15.38)$ & $7(10)$ \\
\hline $\begin{array}{l}\text { Dose altered/ } \\
\text { reduced }\end{array}$ & $22(70.97)$ & $16(41.02)$ & $38(54.28)$ \\
\hline No change & $8(25.81)$ & $17(43.59)$ & $25(35.71)$ \\
\hline \multicolumn{4}{|l|}{$\begin{array}{l}\text { Treatment } \\
\text { Given }\end{array}$} \\
\hline Nil & $18(58.06)$ & $24(61.54)$ & $42(60)$ \\
\hline Symptomatic & $8(25.81)$ & $15(38.46)$ & $23(32.86)$ \\
\hline Specific & $5(16.13)$ & 0 & $5(7.14)$ \\
\hline \multicolumn{4}{|l|}{$\begin{array}{l}\text { Outcome of } \\
\text { ADEs }\end{array}$} \\
\hline Recovered & $26(83.87)$ & 28 (71.79) & $54(77.14)$ \\
\hline Continuing & $2(6.45)$ & $7(17.95)$ & $9(12.86)$ \\
\hline Unknown & $3(9.68)$ & $4(10.26)$ & $7(10)$ \\
\hline
\end{tabular}

$n=$ number of $A D E s$, figure in the parenthesis represent percentage.

Predictability analysis showed that $71.43 \%$ of ADEs were predictable while $28.57 \%$ were not predictable (Table 10).

\section{Preventability assessment by Modified Schumock and Thornton scale}

Preventability of reported ADEs was assessed using the modified Schumock and Thornton scale. On preventability assessment, 28 (40\%) ADEs were found to be not preventable, followed by $21(30 \%)$ probably preventable and definitely preventable ADEs respectively (Table 10).

\section{Direct cost attributable to adverse drug events}

The direct cost incurred to manage these ADEs was also calculated and compared between the two treatment groups. The estimated total direct cost was AED 19,023 (USD 5179), of which cost was observed to be higher in dabigatran group (AED 11, 932; USD 3248) as compared with warfarin group (AED 7,091; USD 1930). The average cost per patient was estimated to be AED $652 \pm$ 703 (USD $177 \pm 191$ ) in dabigatran group as compared 
Table 10: Common Assessment of adverse drug events.

\begin{tabular}{ccccc} 
& \multicolumn{3}{c}{ Categorical Classification } \\
\hline Causality@ & Certain & Probable & Possible & Unlikely \\
No $(\%)$ of ADEs $(\boldsymbol{n}=\mathbf{7 0})$ & $9(12.86)$ & $37(52.86)$ & Severe \\
Severity\# & Mild & Moderate & $4(5.71)$ \\
No $(\%)$ of ADEs $(\boldsymbol{n}=\mathbf{7 0})$ & $26(37.14)$ & $40(57.14)$ & Not preventable \\
Preventability* & Definitely & Probably & $28(40)$ \\
No $(\%)$ of ADEs $(\boldsymbol{n}=\mathbf{7 0})$ & Preventable & preventable & \\
Predictability & $21(30)$ & $21(30)$ & \\
No $(\%)$ of ADEs $(\boldsymbol{n}=\mathbf{7 0})$ & Predictable & Not predictable & \\
\hline
\end{tabular}

n= number of ADEs, figure in the parenthesis represent percentage; @WHO probability scale; \#Hartwig et al. scale, *Modified Schumock and Thornton scale.

to AED $442.6 \pm 278$ (USD $120 \pm 75.69$ ) in warfarin group and the difference was observed to be statistically insignificant.

\section{DISCUSSION}

The present study was carried out in cardiovascular patients suffering from non-valvular atrial fibrillation and receiving at least one anti-thrombotic agent either warfarin or dabigatran as prophylaxis. This was a safety monitoring study which involved primary assessment of ADEs in out-patient clinics or during hospital stay followed by assessment of safety events on follow-up visits at 3 months and 6 months respectively.

Patients prescribed with dabigatran were older in age than the warfarin-treated patients and associated with significantly higher number of co-morbid conditions $(p=0.044)$ and concurrent medications. The present findings are comparable to that of a study conducted earlier. $^{17}$

Male preponderance was observed over female with respect to incidence of ADEs. This could be attributed to clinical condition, atrial fibrillation, which is prevalent among males and advanced age.

In the present study, large number of patients were observed to be on multiple medications signifying polypharmacy. As majority of patients belongs to elderly age group having multiple co-morbidities, they are likely to be on multiple medications.

Patients who were taking concurrent medications, clopidogrel $(p=0.018)$ and non-steroidal anti-inflammatory drugs [NSAIDs] $(p=0.010)$ along with the medications under study, showed significant association with the
ADEs $(p=0.001)$. These drugs are likely to precipitate ADRs when given along the anticoagulants. However, no significant difference was observed among patients who were using $81 \mathrm{mg}$ aspirin in the present study, ${ }^{22}$ unlike that of a study which showed significant risk of bleeding. ${ }^{15}$

On risk assessment, patients were found to have $\mathrm{CHA}_{2} \mathrm{DS}_{2}$-VASC score more than 1 which showed the appropriateness of receiving anticoagulant therapy. The present findings are comparable with the findings of a previous study carried out by Shehab A, et al. (3.54 \pm 1.82 and $3.46 \pm 1.205) .{ }^{17}$ The mean score of HAS-BLED was recorded as $2 \pm 1.02$ which indicates that most of the patients were at low risk of bleeding unlike that of a study conducted earlier. ${ }^{18}$ Further statistical analysis revealed that these predisposing factors were not significantly associated with ADEs.

The incidence of ADEs was high among dabigatran cohort as compared to warfarin cohort which constituted for an overall incidence of $50.6 \%$. These findings are consistent with that of a study conducted earlier by Aslan $\mathrm{O}$ et al. ${ }^{23}$ At the time of follow up, the incidence of ADEs was recorded as $29.6 \%$ at 3 months and $8.1 \%$ at 6 months. This could be due to less intensive monitoring of ADEs post-discharge.

Adverse drug events observed among in-patients during hospital stay were found to be statistically significant. The present findings are comparable to that of a study conducted earlier. ${ }^{24}$ This could be due to intensive monitoring of ADEs and efficient reporting by healthcare professionals.

In the present study, $75 \mathrm{mg}$ and $110 \mathrm{mg}$ dosage strengths of dabigatran were mainly preferred as prophylactic treatment as a part of hospital protocol. Safety events 
were monitored while using these strengths in patients on dabigatran. Dabigatran users were found to have more gastrointestinal bleeding events as compared to warfarin users.

The safety profile was further explored in the patients having tendency to bleed. There were no major bleeding events reported in the present study. However, minor bleeding events were observed in dabigatran cohort as compared to warfarin cohort which is inconsistent with that of a study conducted earlier. Similar profile of bleeding events was observed in a study carried out by Shehab et al. ${ }^{17}$

Gastrointestinal bleeding was the most frequent adverse event among the dabigatran cohort reported earlier in a study which is similar to the present study findings. ${ }^{25}$ One logical reason for increased gastric irritation could be use of a different formulation which is capsule which contains dabigatran-coated pellets with a tartaric acid core. This may partly explain the increased incidence of dyspeptic symptoms with both strengths of dabigatran. ${ }^{26}$ Therefore, the use of gastro-protective agents is advisable prior to dabigatran use.

Dissimilar findings were observed in a previous study. ${ }^{15}$ Another literature revealed elevated liver profile as an adverse effect among dabigatran users which was comparable to that of present study findings. Though less frequent but there was one patient who had experienced elevated alanine aminotransferase (ALT) levels of three times than the upper normal limit. ${ }^{26}$ This initiates discussion about having standard recommendations for monitoring liver function tests (LFTs) prior to and after using dabigatran.

Elevated coagulation profile was the most common ADE observed among warfarin cohort followed by anemia, rectal bleed, hemoptysis and skin bruises. These findings were dissimilar to that of a study conducted earlier by Aslan $\mathrm{O}$ et al. where dyspepsia (18.3\%), headache (16.4\%), nausea/vomiting (11.9\%) and dizziness (10\%) were reported. ${ }^{24}$ Another study by Hanlon et al. on monitoring ADRs in elderly patients, the common ADRs with anticoagulants (i.e., warfarin) observed were gastrointestinal bleeding, epistaxis and hematuria. ${ }^{25}$ The type of ADEs observed with dabigatran was mild gastritis like symptoms (dyspepsia) apart from ADEs related to bleeding which was common in both the groups. The present findings of both cohorts were comparable to studies carried out by Hori et al. (16.1\%), Connolly et al. $(11.8 \%)$ and Ansal et al. (21.9\%)..$^{18,22,23}$

In terms of management of ADEs, majority of the reactions were managed by dose reduction and without any change in treatment. Drug was withdrawn in some cases. The finding observed in the present study was in contrast with that of a study conducted by Gholmai et al. where $65 \%$ of the ADEs were managed by without change in the treatment schedule. ${ }^{27}$ Further observation in a previous study showed that the management of ADEs was done by withdrawal of a suspected drug (47.28\% vs. $47.5 \%$ ). ${ }^{28}$ However, few ADEs were treated by administering the specific antidotes (Vitamin K) in case of warfarin induced bleeding $(7.14 \%)$ while there was no antidote recommended for patients receiving dabigatran.

In dabigatran cohort, symptomatic treatment was given in almost one third of ADEs with pantoprazole $40 \mathrm{mg}$, hyoscine bromide $10 \mathrm{mg}$, fresh frozen plasma and Prothrombin Coagulation Complex (PCC). These findings are in par with the study of M.A. Smythe et al. where the authors used the same treatment for the management of bleeding. Idarucizumab is a recently introduced drug in Europe and USA for the reversal of anticoagulant effects of dabigatran in life-threatening situations which is currently not available in UAE. ${ }^{29}$

The outcome of ADEs suggested that majority of cases completely recovered, however, reaction continued in few patients. The outcome was unknown in few cases. This finding could be due to their premature death or inability to come for follow-up. The mortality observed during the study was not associated with adverse drug events as the patient died due to complications of the existing medical condition which can be further supported by studies. ${ }^{1724}$

In the present study, suspected drugs were suspended or withheld in 22 patients which showed resolution of ADEs which is in line with that of a previous study. ${ }^{30}$ Re-challenge was considered among these patients in view of their ongoing treatment but in 4 patients, the ADE reappeared, thereby confirming the evidence of causal relationship.

On causality assessment, majority of ADEs were observed as probable in nature as per WHO probability scale. The findings observed in the present study are similar to that of a previous study carried out by Davis et al. ${ }^{31}$

According to this study, majority of suspected ADEs were found to be moderate in nature. Moderate reactions, that were frequent, resulted in the extension of hospital stay by more than 2 days. This finding is inconsistent with that of a study conducted earlier which reported more number of mild reactions [mild reactions: (53\% vs. $79.23 \%)] .^{30}$

Indian Journal of Pharmacy Practice, Vol 13, Issue 2, Apr-Jun, 2020 
Predictability assessment showed that most of the ADEs were predictable and well documented with incidence rate greater than $10 \%$ in the literature. This finding is comparable to that of a previous study. ${ }^{32}$ The observed ADEs were assessed for preventability using modified Schumock and Thornton scale which revealed that majority were not preventable whereas the rest of them were probably preventable and definitely preventable. This observation is similar to that of a study carried out by Wadhwa et al. where $83.84 \%$ ADEs were not preventable. $^{30}$

The overall direct cost was estimated to be AED 19,023, which is inclusive of cost in both the treatment groups (warfarin: AED 7,091; dabigatran: AED 11,932). Higher cost in dabigatran was observed probably due to the use of prothrombin complex concentrate which is a costly product (approx. 3000 dirhams). This product was used to manage life threatening situation in the present study. There is no published data available in the Middle-Eastern countries regarding the cost burden due to ADEs. A study performed by Gyllensten et al. in Europe reported that the average direct cost per patient was 444.9 US dollars among 596 patients. ${ }^{33}$ In the present study, the average cost per patient was estimated to be AED 652 \pm 703 in dabigatran group and AED 442.6 \pm 278 in warfarin group which was not statistically significant. There were four severe ADE cases observed which were treated intensively in critical care unit (CCU). This might have further contributed for the increment of direct cost in both the treatment groups.

Various studies that are carried out before to compare the safety and efficacy of dabigatran and warfarin in atrial fibrillation patients had demonstrated superiority of dabigatran over warfarin. ${ }^{15,16,22}$ The results of these studies have also highlighted safety issues associated with dabigatran such as gastrointestinal effects and bleeding tendencies. Among elderly population lowdose dabigatran was associated with high risk of gastrointestinal bleeding compared to warfarin, however, no difference was seen in the treatment outcome. ${ }^{34,35}$ Shehab et al. studied the clinical utility of dabigatran among the UAE population showed that $23.7 \%$ patients had bleeding events. ${ }^{17}$ Apart from clinical trials, most of the studies were performed retrospectively by retrieving the data from registries. However, the only available prospective study comparing these two drugs on the Danish population which has followed up the enrolled patients for a duration of $\geq 1$ year. ${ }^{15}$ Hence, the present study is the first of its kind performed in the Gulf region population to evaluate the safety of dabigatran over warfarin.
The present study was a non-randomized study which was carried out at a single center for short duration. Study design and duration restrict to generalize the findings. Furthermore, studies are required to be conducted at multicenter involving large population and extending the follow-up duration to more than six months. Less number of reactions were observed during 3 -months or 6-months follow up period. Monitoring long term effects of drugs over extended period (more than one year) can provide better insight about the safety of ongoing treatment.

In the present study, emphasis has been given to data reported for out-patients as well as in-patients during study period. Follow-up data cannot be presented due to inadequate information about ADEs. However, utmost care was taken to avoid drop-outs and lost to follow-up cases.

Medication Errors (ME) were not monitored during the study period. Awareness regarding the importance of monitoring and reporting ADEs can improvise the ADE reporting practices in a hospital setting.

Language was one of the barriers while interacting with patients as most of them were locals. It was overcome by taking proper support from nurses in translating the terms and conveying information to patients.

\section{CONCLUSION}

In the present study, dabigatran appears to be safer than warfarin. Less frequent PT/INR monitoring, reduction in bleeding events and safer administration being the most probable reasons for preferring dabigatran in non-valvular atrial fibrillation patients. Dabigatran being a costly alternative is most commonly preferred by healthcare professionals for the prevention of thrombotic stroke in NVAF. Dabigatran is associated with gastro intestinal adverse effects and therefore, utmost care should be exercised to prevent gastrointestinal (GI) adverse effects and ensure patient compliance. Patients who are at high risk of developing adverse effects especially bleeding events should be encouraged for voluntary reporting and be critically reviewed for their medication regimen during hospitalization and in the outpatient setting.

\section{ACKNOWLEDGEMENT}

Authors wish to thank RAK Medical and Health Sciences University, Ras Al-Khaimah, UAE and Ibrahim Bin Hamad Obaidallah Hospital, Ras Al-Khaimah, UAE for their constant support and cooperation in the successful completion of this study. We also thank Dr. Sathvik B. Sridhar for his support extended towards statistical 
evaluation of study data.

\section{CONFLICT OF INTEREST}

The authors declare no conflict of interest.

\section{ABBREVIATIONS}

ACC: American College of Cardiology; ADEs: Adverse Drug Events; ADRs: Adverse Drug Reactions; AF: Atrial Fibrillation, AHA: American Heart Association; ALT: Alanine Aminotransferase; DDI: Drug-Drug Interaction; FDA: Food and Drug Administration; GI: Gastrointestinal; INR: International Normalized Ratio; KSA: Kingdom of Saudi Arabia; LFTs: Liver Function Tests; NOACs: Novel Oral Anti-coagulants; NSAIDs: Non-Steroidal Anti-Inflammatory Drugs; NVAF: Non-valvular Atrial Fibrillation; PCC: Prothrombin Coagulation Complex; PT: Prothrombin time; UAE: United Arab Emirates; WHO: World Health Organization.

\section{SUMMARY}

Dabigatran being a costly alternative is most commonly preferred by healthcare professionals for the prevention of thrombotic stroke in NVAF. Dabigatran appears to be safer than warfarin. Less frequent PT/INR monitoring, reduction in bleeding events and safer administration being the most probable reasons for preferring dabigatran in non-valvular atrial fibrillation patients.

\section{REFERENCES}

1. Janer AL. Applied therapeutics: The clinical use of drugs. Philadelphia: Lippincott Williams and Wilkins. 2013;496-8.

2. Lip GY, Brechin CM, Lane DA. The global burden of atrial fibrillation and stroke: A systematic review of the epidemiology of atrial fibrillation in regions outside North America and Europe. Chest. 2012;142(6):1489-98.

3. Benjamin EJ, Wolf PA, D'Agostino RB, Silbershatz H, Kannel WB, Levy D. Impact of atrial fibrillation on the risk of death: The Framingham Heart Study. Circulation. 1998;98(10):946-52.

4. Ganz LI, Spragg D. Epidemiology of and risk factors for atrial fibrillation. 2015. [cited 2015 Jun 11]. Available from: UpToDate.

5. Zubaid M, Rashed WA, Alsheikh-Ali AA, AIMahmeed W, Shehab A, Sulaiman K, et al. Gulf Survey of Atrial Fibrillation Events (Gulf SAFE) Design and baseline characteristics of patients with atrial fibrillation in the Arab Middle East. Circ Cardiovasc Qual Outcomes. 2011;4(4):477-82.

6. Banerjee A, Fauchier L, Vourc'h P, Andres CR, Taillandier S, Halimi JM, et al. Renal impairment and ischemic stroke risk assessment in patients with atrial fibrillation: The Loire Valley Atrial Fibrillation Project. J Am Coll Cardiol. 2013;61(20):2079-87.

7. Gutierrez C, Blanchard DG. Atrial Fibrillation: Diagnosis and treatment. Am Fam Physician. 2011;83(1):61-8.

8. Hanley CM, Kowey PR. Are the novel anticoagulants better than warfarin for patients with atrial fibrillation?. J Thorac Dis. 2015;7(2):165-71.

9. Crissey L. FDA approves Pradaxa, marking a major milestone to reduce the risk of stroke in patients with non-valvular atrial fibrillation. Boehringer Ingelheim. 2010. [cited 24 November 2015]. Available from:http://us.boehringeringelheim. com/newsevents/press_releases/press_release_archive/2010/ october_20_2010.html
10. Schneeweiss S, Gagne JJ, Patrick AR, Choudhry NK, Avorn J. Comparative efficacy and safety of new oral anticoagulants in patients with atrial fibrillation. Circ Cardiovasc Qual Outcomes. 2012;5(4):480-6.

11. Chang HY, Zhou M, Tang W, Alexander GC, Singh S. Risk of gastrointestinal bleeding associated with oral anticoagulants: Population based retrospective cohort study. BMJ. 2015;350:h1585.

12. Lazarou J, Pomeranz BH, Corey PN. Incidence of adverse drug reactions in hospitalized patients: A meta-analysis of prospective studies. JAMA. 1998;279(15):1200-5.

13. Classen DC, Pestotnik SL, Evans RS, Lloyd JF, Burke JP. Adverse drug events in hospitalized patients. Excess length of stay, extra costs and attributable mortality. JAMA. 1997;277(4):301-6.

14. Thomas EJ, Studdert DM, Newhouse JP, Zbar BI, Howard KM, Williams EJ, et al. Costs of medical injuries in Utah and Colorado. Inquiry. 1999;36(3):255-64.

15. Larsen TB, Rasmussen LH, Skjøth F, Due KM, Callréus T, Rosenzweig M, et al. Efficacy and safety of dabigatran etexilate and warfarin in "real-world" patients with atrial fibrillation: A prospective nationwide cohort study. J Am Coll Cardiol. 2013;61(22):2264-73.

16. Lauffenburger JC, Farley JF, Gehi AK, Rhoney DH, Brookhart MA, Fang G. Effectiveness and safety of dabigatran and warfarin in real-world US patients with non-valvular atrial fibrillation: A retrospective cohort study. J Am Heart Assoc. 2015;4(4):e001798.

17. Shehab A, Elnour AA, SadikA, Mandil MA, AIShamsi A, Suwaidi AA, et al. Clinical utility of dabigatran in United Arab Emirates. Saudi Med J. 2015;36(11):1290-8.

18. Hori M, Connolly SJ, Zhu J, Liu LS, Lau CP, Pais P, et al. Dabigatran versus warfarin: Effects on ischemic and hemorrhagic strokes and bleeding in Asians and non- Asians with atrial fibrillation. Stroke. 2013;44(7):1891-96.

19. Freeman JV, Zhu RP, Owens DK, Garber AM, Hutton DW, Go AS, et al. Costeffectiveness of dabigatran compared with warfarin for stroke prevention in atrial fibrillation. Ann Intern Med 2011;154(1):1-11.

20. Sorensen SV, Peng S, Monz BU, Bradley-Kennedy C, Kansal AR. A comparative analysis of models used to evaluate the cost-effectiveness of dabigatran versus warfarin for the prevention of stroke in atrial fibrillation. Pharmacoeconomics. 2013;31(7):589-604.

21. Johnston KM, Osenenko KM, Qatami L, Donato BM, Alsheikh-Ali AA, Binbrek AS, et al. Health care resource utilization and costs in individuals with atrial fibrillation in United Arab Emirates and Kingdom of Saudi Arabia: A retrospective cohort study. International Journal of Internal Medicine. 2015;4(2):17-25.

22. Ezekowitz MD, Reilly PA, Nehmiz G, Simmers TA, Nagarakanti R, ParchamAzad $\mathrm{K}$, et al. Dabigatran with or without concomitant aspirin compared with warfarin alone in patients with nonvalvular atrial fibrillation (PETRO Study). Am J Cardiol. 2007;100(9):1419-26.

23. Aslan O, Yaylali YT, Yildirim S, Yurtdas M, Senol H, Ugur-Yildiz M, et al. Dabigatran versus warfarin in atrial fibrillation: Multicenter experience in Turkey. Clin Appl Thromb Hemost. 2016;22(2):147-52.

24. Bouvy JC, DeBruin ML, Koopmanschap MA. Epidemiology of adverse drug reactions in Europe: A review of recent observational studies. Drug Saf. 2015;38(5):437-53.

25. Hanlon JT, Pieper CF, Hajjar ER, Sloane RJ, Lindblad Cl, Ruby CM, et al. Incidence and predictors of all and preventable adverse drug reactions in frail elderly persons after hospital stay. J Gerontol A Biol Sci Med Sci. 2006;61(5):511-5.

26. Connolly SJ, Ezekowitz MD, Yusuf S, Eikelboom J, Oldgren J, Parekh A, et al. Dabigatran versus warfarin in patients with atrial fibrillation. $\mathrm{N}$ Engl J Med 2009;361(12):1139-51.

27. Gholami K, Shalviri G. Factors associated with preventability, predictability and severity of adverse drug reactions. Ann Pharmacother. 1999;33(2):236-40.

28. Kaur S, Kapoor V, Mahajan R, Lal M, Gupta S. Monitoring of incidence, severity and causality of adverse drug reactions in hospitalized patients with cardiovascular disease. Indian J Pharmacol. 2011;43(1):22-6.

29. FDAApproves Praxbind $₫$ (idarucizumab), Specific Reversal Agent for Pradaxa $₫$ (dabigatran etexilate). Boehringer-ingelheim. 2016. Boehringer-ingelheim.com. [cited 28 May 2016]. Available from: https://www.boehringer-ingelheim.com/ press-release/fda-approves-praxbind-idarucizumab-specific-reversal-agentpradaxa-dabigatran.

30. Wadhwa T, Patil PA, Suresh VP. Monitoring adverse drug reactions in coronary thrombosis patients admitted to intensive cardiac care unit in a tertiary care hospital. Indian Journal of Pharmacy Practice. 2013;6(1):6-12.

Indian Journal of Pharmacy Practice, Vol 13, Issue 2, Apr-Jun, 2020 
31. Davies EC, Green CF, Taylor S, Williamson PR, Mottram DR, Pirmohamed M. Adverse drug reactions in hospital in-patients: A prospective analysis of 3695 patient-episodes. PLoS One. 2009;4(2):e4439.

32. Shamna M, Dilip C, Ajmal M, Mohan PL, Shinu C, Jafer CP, et al. A prospective study on adverse drug reactions of antibiotics in a tertiary care hospital. Saudi Pharm J 2014;22(4):303-308.

33. Gyllensten H, Hakkarainen KM, Hägg S, Carlsten A, Petzold M, Rehnberg C, et al. Economic impact of adverse drug events. A retrospective population-based cohort study of 4970 adults. PLoS One. 2014;9(3):e92061.
34. Graham D, Reichman ME, Wernecke M, Zhang R, Southworth MR, Levenson $\mathrm{M}$, et al. Cardiovascular, bleeding and mortality risks in elderly Medicare patients treated with dabigatran or warfarin for nonvalvular atrial fibrillation. Circulation. 2015;131(2):157-64.

35. Avgil-Tsadok M, Jackevicius CA, Essebag V, Eisenberg MJ, Rahme E, Behlouli $\mathrm{H}$, et al. Dabigatran use in elderly patients with atrial fibrillation. Thromb Haemost 2016;115(1):152-60. 